\title{
Correction to: Effectiveness of Nutrition Intervention in a Selected Group of Overweight and Obese African-American Preschoolers
}

\author{
Yulyu Yeh $^{1,2}$ - Kathryn Brogan Hartlieb ${ }^{1,3}$ - Cynthia Danford ${ }^{1,4}$ • K.-L. Catherine Jen ${ }^{1}$
}

Published online: 26 October 2017

(C) W. Montague Cobb-NMA Health Institute 2017

\section{Correction to: J. Racial and Ethnic Health Disparities https://doi.org/10.1007/s40615-017-0399-0}

The third author's correct Family Name is Danford. The fourth author's correct Family Name is Jen.

Part of our original analyses was performed with overweight and obese preschoolers only. This procedure may have created a subgroup of individuals with extreme values at baseline and this may likely be inappropriate. It is conceivable that these subjects were in an extreme state when they were measured at baseline and that over time, one would expect them to regress back to a more normal state, independent of any intervention. We did not take into consideration the phenomenon called regression to the mean $[1,2]$. As a result, we cannot make any affirmative statements about the effectiveness of our interventions since a) there were no differences in changes in BMI percentile among the three groups when all preschoolers were analyzed together; and b) in the subgroup of overweight and obese preschoolers, all three groups, including the controls, regressed back towards a more normal state, even though the changes observed in intervention Group A were not statistically significant.

\section{References}

1. Skinner AC, Goldsby TU, Allison DB. Regression to the mean: a commonly overlooked and misunderstood factor leading to unjustified conclusions in pediatric obesity research. Childhood. Obesity. 2016;12:155-8.

2. Bland JM, Altman DG. Best (but oft forgotten) practices: testing for treatment effects in randomized trials by separate analyses of changes from baseline in each group is a misleading approach. Am J Clin Nutr. 2015;102:991-4.
The online version of the original article can be found at https://doi.org/ 10.1007/s40615-017-0399-0

\footnotetext{
K.-L. Catherine Jen

cjen@wayne.edu

1 Wayne State University, Detroit, MI, USA

2 Texas A \& M University, College Station, TX, USA

3 Florida International University, Miami, FL, USA

4 University of Pittsburg, Pittsburg, PA, USA
} 